\title{
Effect of Metal Ion Exchange Modification of Zeolite on Sulfide Removal Performance
}

\author{
Zhu Li-Jun ${ }^{1, \text { a,*}, ~ H u a n g ~ C h a o ~}{ }^{1}$, Wang Yong-Jie ${ }^{1}$, Lv Xin-Feng $^{1}$ Huang Jia-Wei ${ }^{1}$, Bai Yan ${ }^{2}$, Li \\ Jin-Feng ${ }^{3}$ and Huang Xiao-Jin ${ }^{4}$ \\ ${ }^{1}$ State Key Laboratory of Heavy Oil, College of Chemical Engineering, China University of \\ Petroleum, No.66, Changjiang West Road, Qingdao, 266580, China \\ 2 Shandong Qiyang Petrochemical Engineering Company LTD., Qingdao, China \\ ${ }^{3}$ Jining Technician College, Chongwen Road, High-tech Zone, Jining, China \\ ${ }^{4}$ Shandong Public Holdings Co., Ltd., China \\ *corresponding author, ${ }^{\mathrm{a}}$ zhulj2002@163.com
}

\begin{abstract}
Copper-modified 13X Zeolite was prepared by impregnation of metal nitrate solution with ion exchange and combined with calcination, and its application in desulfurization of fuel oil was investigated. Different anions have a great influence on the performance of modified adsorbents. Chloride ions are better than nitrate and better than bromide ions. After characterization, the $13 \mathrm{X}$ zeolite modified by different anion copper salts have little influence on the crystal structure of 13X molecules. Due to the influence of the solubility on the impregnation or the adsorption capacity of the extra nuclear electronic arrangement on the sulfide, the $\mathrm{CuCl}$ is significantly better than other ions. Desulfurization performance after calcination is better than that before calcination, and calcination does not oxidize cuprous ions. After optimization, the prepared CuCl-impregnated 13X zeolite have the best adsorption properties and good reusability.
\end{abstract}

Keywords: Ion exchange, Modified, 13X zeolite, Sulfide removal.

\section{Introduction}

The direct emission of SOx from the combustion of sulfur-containing compounds in fuel oil to the atmosphere can cause serious environmental pollution, and the deep removal of sulfides from fuel oil has become an urgent topic worldwide [1]. On January 1, 2018, the whole country will implement the fifth phase of national vehicle emission standards. The corresponding oil products have also been upgraded to the National Five Standard. The country's five standard of gasoline limits the sulfur content particularly stringently, and the sulfur content index limit is reduced to 10ppm from the fourth stage of $50 \mathrm{ppm}$. The generation of ultra-low sulfur content gasoline poses new challenges for refineries. The low hydrodesulfurization reactivity of benzothiophene sulfur compounds in gasoline is a key target for refinery desulfurization. This is because traditional hydrodesulfurization technology is limited by the thermodynamic equilibrium and needs to be carried out under high temperature and high pressure operating conditions, resulting in high operating costs, destroying the main components in gasoline, and reducing the octane number of gasoline. Therefore, many researchers have devoted themselves to the research of non-hydrogenation ultra-deep desulfurization technology for gasoline, and the adsorption desulfurization reaction conditions are mild, high selectivity, simple operation, high desulfurization rate, and are the most potential ultra-deep desulfurization technology [1]. It has attracted wide attention from all countries in the world.

The key to adsorption desulfurization is to increase the sulfur capacity of the adsorbent, and the surface acidity of the adsorbent is a key factor affecting the capacity of the adsorbent to adsorb sulfur [2-3].

Adsorption desulfurization of zeolite is a physical change process. The main cause of adsorption is a "surface force" produced by the action of molecular attraction on the surface of solids. Sulfide 
molecules in gasoline collide with the surface of the adsorbent and cause molecular condensation on the surface, which reduces the number of molecules in the fluid. So this achieves the separation and removal of sulfides. Ion exchange refers to the exchange of compensation cations outside the framework of the zeolite molecular sieve. The compensating ions outside the framework of zeolite are generally protons and alkali or alkaline earth metals, which are easily ion-exchanged into various valent metal ion-type zeolite in an aqueous solution of a metal salt, thereby achieving the purpose of modifying molecular sieves [4].

For example, Shao Xinchao et al. [5] investigated the adsorption capacity of SBA-15 on sulfides in FCC gasoline after $\mathrm{Cu}$ modification. The results showed that $\mathrm{Cu}$ was successfully loaded on the surface of SBA-15, which increased the amount of L acid in molecular sieves, thereby increasing the The adsorption capacity of SBA-15 indicates that $\mathrm{Cu}$ plays an important role in the desulfurization process. Shan Jiahui et al. [6] prepared a CuCl-supported SBA-15 molecular sieve desulfurization adsorbent using a thermal dispersion method. Yu Qixin et al. [7] loaded Ag, Ni, and other metal ions on the surface of activated carbon by impregnation method. The desulfurization capacity of the metal-organic adsorbent formed has been improved to some extent.

At present, most of the studies on adsorption desulfurization aim at removing the thiophene sulfur compounds in gasoline by using the metal-modified molecular sieve as an adsorbent. However, in the modification process, the ion selection and preparation methods have not been studied in depth. Therefore, the authors will conduct in-depth research on $\mathrm{Cu}$, systematic studies on ion selection, preparation methods, etc., and used to simulate gasoline adsorption desulfurization experiments to achieve further improvement in desulfurization performance.

\section{Experimental sections}

\subsection{Adsorbent preparation}

Preparation method of uncalcined adsorbent: A $0.02 \mathrm{~mol} / \mathrm{L}$ aqueous solution of metal salt was prepared and mixed with $3 \mathrm{~g}$ of 20-40 mesh $13 \mathrm{X}$ molecular sieves and heated at $70^{\circ} \mathrm{C}$. for $4 \mathrm{~h}$. Then rinse with plenty of deionized water and filter by suction. It was then dried at $100^{\circ} \mathrm{C}$ for $6 \mathrm{~h}$ under vacuum to obtain a modified uncalcined adsorbent.

Preparation method of calcination adsorbent: A $0.02 \mathrm{~mol} / \mathrm{L}$ aqueous solution of a metal salt was prepared and mixed with $3 \mathrm{~g}$ of $20-40$ mesh $13 \mathrm{X}$ molecular sieves and heated at $70^{\circ} \mathrm{C}$. for $4 \mathrm{~h}$. Then rinse with plenty of deionized water and filter by suction. It was then vacuum-dried at $100^{\circ} \mathrm{C}$ for $6 \mathrm{~h}$, then placed in a muffle furnace at $500^{\circ} \mathrm{C}$ and calcined for 3.5 hours to obtain a calcined adsorbent.

\subsection{Adsorbent characterization}

After the sample was vacuum dried at $100^{\circ} \mathrm{C}$ for 5 hours, the sample was ground to a powder for XRD analysis. The X'Pert Pro MPD polycrystalline powder X-ray diffractometer manufactured by Panalytical in the Netherlands was used. Test conditions: $\mathrm{Cu}$ target, K $\alpha$ radiation source $(\lambda=0.15406$ $\mathrm{nm}$ ), tube voltage $40 \mathrm{kV}$, tube flow $40 \mathrm{~mA}$. X-ray phase analysis scanning speed $5.0 \% \mathrm{~min}$.

\subsection{Adsorption desulfurization performance}

Preparation of Sulfide-containing Simulated Oil Products: Take about $90 \mathrm{~mL}$ of n-heptane and 100 $\mathrm{mL}$ volumetric flask, and take $4 \mu \mathrm{L}$ of benzothiophene (or dibenzothiophene) with a microsyringe, slowly add it to a volumetric flask, then bring to volume with n-heptane to $100 \mathrm{~mL}$, and shake well until it is uniformly mixed. .

Desulfurization: Take $0.0680 \mathrm{~g}$ of adsorbent in a $10 \mathrm{ml}$ vial, add $3 \mathrm{~mL}$ of sulfur-containing simulated gasoline, stir at room temperature with electromagnetic stirring, and sample $100 \mu \mathrm{L}$ per time to disperse into $2 \mathrm{~mL}$ of n-heptane, and measure the absorbance. Calculate the desulfurization rate by Formula 1.

$$
\text { Desulfurization rate }=\frac{A}{A_{0}-A}
$$

In the formula: $\mathrm{A}$ is the absorbance measured at the time of sampling, and A0 is the absorbance when no adsorbent is added. 


\section{Results and Discussion}

\subsection{Screening of preparation conditions}

Table 1 Effects of metal ions and preparation conditions of the adsorption performance

\begin{tabular}{cccc}
\hline Item & Metal salt & Calcination & Sulfur removal rate \\
\hline 1 & $\mathrm{Cu}(\mathrm{NO} 3) 2$ & Yes & 27.2 \\
2 & $\mathrm{CuCl} 2$ & Yes & 38.6 \\
3 & $\mathrm{CuBr} 2$ & Yes & 24.6 \\
4 & $\mathrm{CuCl}$ & Yes & 73.2 \\
5 & $\mathrm{CuCl}$ & No & 71.5 \\
\hline
\end{tabular}

From the results of Table 1, it can be seen that copper ions are also the same, and different anions have a great influence on the adsorption performance. Obviously, it can be seen that the cuprous ions are significantly better than the copper ions, which indicates that the electron results of the cuprous ions have a strong ability to coordinate with the sulfides, and they are more likely to form feedback bonds with the sulfides, and thus have a stronger ability to adsorb sulfides. Comparing different anions, it was found that chloride ions are better than nitrate and better than bromide ions. This may be because the difference in the solubility of different copper salts leads to different diffusion rates during the impregnation process, which affects the ion exchange efficiency and thus the desulfurization performance.

\subsection{Reuse performance inspection}

The desulfurization rates of the adsorbent after repeated use were: $72.3 \%, 68.5 \%$ and $67.3 \%$ respectively. From the results, it can be seen that the $13 \mathrm{X}$ molecules modified by cuprous ion have good sulfide adsorption performance. With the increase of the number of cycles, the adsorption performance is basically not reduced. This shows that the cuprous ion undergoes ion exchange in molecular molecules and has good stability.

\subsection{Characterization of adsorbents}

(1) Effects of different anions

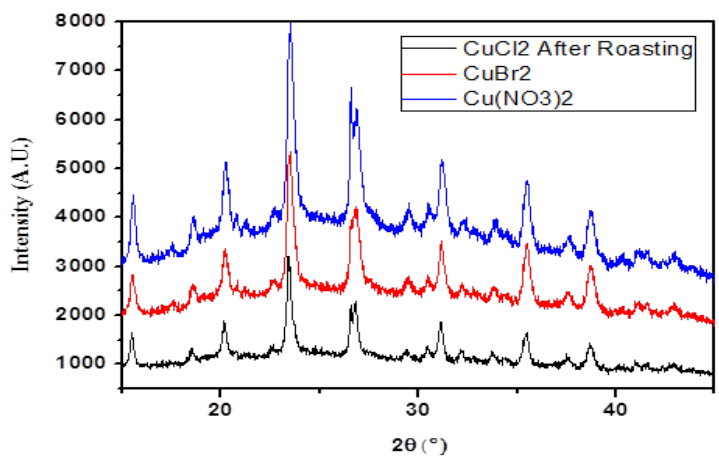

Fig.1 XRD patterns of zeolites prepared by impregnation of different anionic copper salts

From the XRD pattern (Fig. 1), it can be seen that the 13X molecular sieves modified by different anionic copper salts have little influence on the crystal structure of $13 \mathrm{X}$ molecules, and the $13 \mathrm{X}$ molecular sieve characteristic diffraction peaks are all present. The crystallinity is different after modification of the copper salts of different anions. After the nitrate modification, the crystallinity is best. This may be the least destructive effect of nitrates on the molecular sieve during impregnation.

(2) Influence of different valences of ion

After modified by $\mathrm{CuCl}$ and $\mathrm{CuCl} 2$ (Fig. 2a), compared with the modification of different anionic copper salts, the molecular sieve has a greater influence, and it may also be the diffraction peak of cuprous ion. The existing diffraction peaks of the existing $13 \mathrm{X}$ molecular sieve exist. In addition, new diffraction peaks appear at $13^{\circ}, 33^{\circ}$ and $43^{\circ}$, which may be the crystalline state of cuprous chloride. 

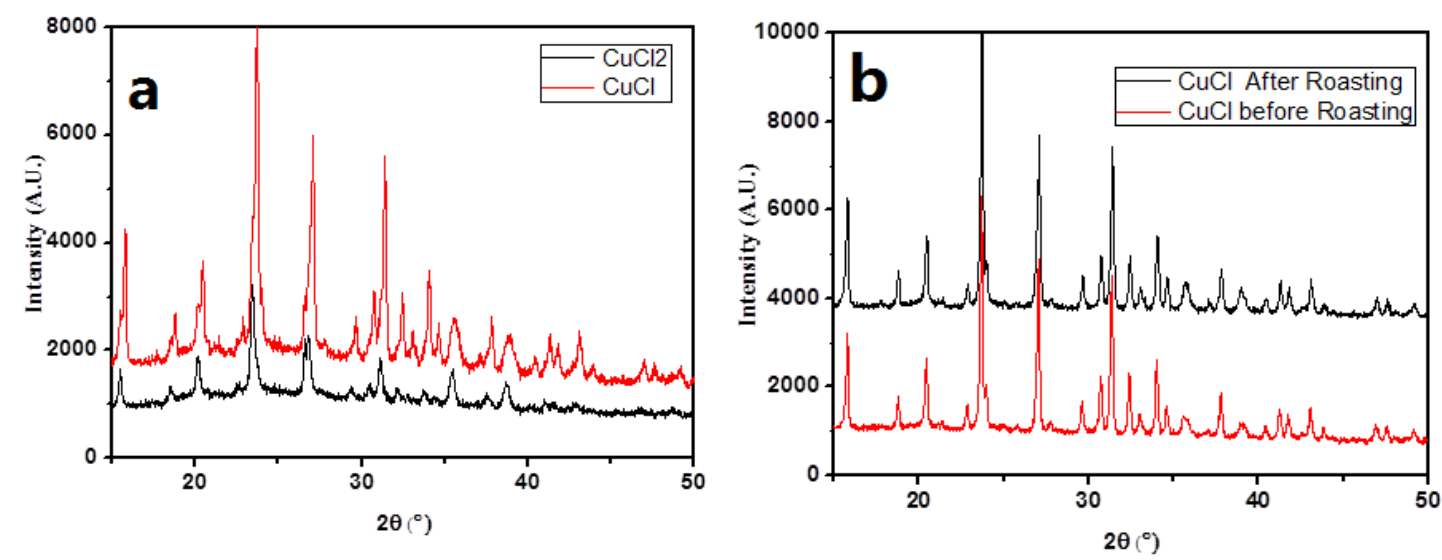

Fig. 2 XRD pattern of zeolite prepared by impregnation of different valence copper salts (a) and before and after calcination

(3) Effect of calcination

Comparing the XRD before and after calcination (Fig. 2b3), it was found that the diffraction peaks before and after calcination changed little, indicating that the cuprous ions were not oxidized to copper ions after calcination. This also indicates that during the impregnation process, cuprous ions are also molecular sieve ions. Exchanges have taken place, which has increased stability and is not easily oxidized by air.

\section{Conclusions}

The 13X molecular sieve was modified by the copper salt impregnation method. After the influence of different anions, the investigation of the $\mathrm{Cu}$ valence and the calcination, it was found that the $\mathrm{CuCl}$ ion calcination modification had the best performance and the thiophene removal rate reached $73.2 \%$. After repeated tests and evaluations, it was found that there was no significant decrease in performance after three uses, indicating that $\mathrm{Cu}$ ions can be exchanged with the surface of the molecular sieve by impregnation. The desulfurization performance of the modified adsorbent was improved, and the repeated use performance was good.

\section{Acknowledgments}

This work is supported by the Fundamental Research Funds for the Central Universities of China (18CX02118A) and China University of Petroleum (East China) Research Startup Fund.

\section{References}

[1] Dehghan R, Anbia M. Zeolites for adsorptive desulfurization from fuels: A review. Fuel Processing Technology, 2017, 167:99-116

[2] Moradi M, Karimzadeh R, Moosavi E S. Modified and ion exchanged clinoptilolite for the adsorptive removal of sulfur compounds in a model fuel: New adsorbents for desulfurization. Fuel, 2018, 217:467-477.

[3] Prajapati Y N, Verma N. Fixed bed adsorptive desulfurization of thiophene over Cu/Ni-dispersed carbon nanofiber. Fuel, 2018, 216:381-389.

[4] Bhandari V M, Chang H K, Park J G, et al. Desulfurization of diesel using ion-exchanged zeolites[J]. Chemical Engineering Science, 2006, 61(8):2599-2608.

[5] Shao X C, Duan L H, Wu Y Y, et al. Effect of Surface Acidity of CuO-SBA-15 on Adsorptive Desulfurization of Fuel Oils. Acta Physico-Chimica Sinica, 2012, 28(6):1467-1473(7)..

[6] Shan J H, Liu X Q. Adsorption of sulfur-containing compounds on CuCl/SBA-15 molecular sieve prepared by the thermal diffusion method. Journal of Functional Materials, 2010, 41(12):2194-2197.

[7] Yu M X, Li Z, Xia Q B, et al. Adsorption of dibenzothiophene on activated carbons loaded with different metal ions. Journal of Functional Materials, 2006, 37(11):1816-1818. 